\title{
EDITORIAL: COVID is still with us
}

N LAST year's final edition we joked that we would eventually come to use $\mathrm{BC}$ to stand for Before COVID and AD for After the Donald. Well, Donald Trump is out of office, but COVID-19 is still with us, laying waste to countries, engendering all sorts of insane conspiracy theories and threatening the lives of journalists trying to cover the pandemic. As founding editor Professor David Robie argues in the introductory article of our Commentary section:

One of the biggest challenges of all has been an 'infodemic' of misinformation and falsehoods peddled by many through social media postings which have contributed to a serious vaccine hesitancy problem in many countries, particularly where education is limited (Estella, 2020).

Another major challenge has been the personal risk for many journalists covering this pandemic that, according to arguably the most reliable public statistics monitor, the John Hopkins University Coronavirus Resource Centre (COVID-19 Dashboard, 2021) case tracker, had infected more than 207 million people and caused more than 4.3 million deaths globally at the time of writing.

As this editorial is being written New Zealand is about to enter our sixth week of Level Four lockdown in Auckland and our colleagues around the world have been facing similar strains of lockdowns, vaccinations and restrictions. We are extremely grateful to our contributors for their patience as this edition has been put together.

This is the first edition of Pacific Journalism Review to be produced as an independent venture since David's retirement from Auckland University of Technology. PJR was produced through the Pacific Media Centre at AUT, but the sudden closure of the centre after his departure and doubts as to whether it will reopen, means that we have taken a different path.

Different though the path might be, David and the rest of the editorial staff remain deeply committed to the journal as an independent publication and maintaining the standards set by PJR since it was founded at the University of Papua New Guinea in 1994. This is our second double edition and as usual we have drawn on articles by writers around New Zealand, Australia, the Pacific and Southeast Asia. We pride ourselves on being 'different' and opening our pages to authors from widely different disciplines and from academics and industry practitioners.

As David said recently: 'We are at a critical crossroads for the future because increasingly the Northern hegemony of global research means journals are becoming oppressively bland. I believe we have a very distinctively different sort of journalism and communication research journal — eclectic and refreshing.' 


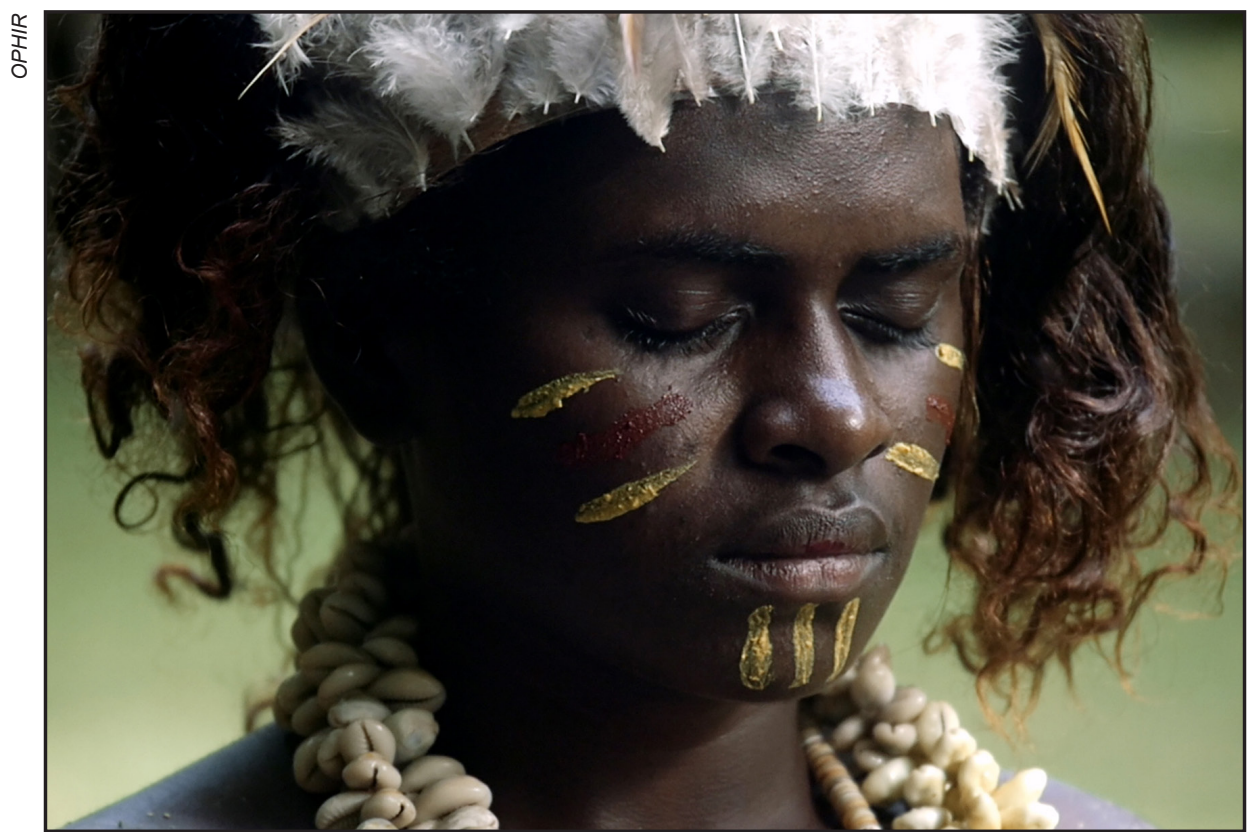

Figure 1: Frontline in this edition features Ophir, an investigative documentary depicting the Bougainville Civil War.

The virtues of being different and eclectic are reflected in our academic standing; we have just been restored by the global journal metrics monitor SCImago to Q2 ranking (bit.ly/3ETs1 lm), which is where we were already in 2015, but we had slipped slightly to the top of Q3, even though we believe the journal has steadily improved in spite of many challenges and limited resources.

This edition has been edited by David Robie and Philip Cass in Auckland, with Del Abcede, as usual, taking the strain on the layouts and design. We have been ably assisted by assistant editor Khairiah Rahman, who has been the first port of call for submissions and correspondence. In Sydney, Wendy Bacon edited our Frontline section in partnership with Nicole Gooch, who has also been our reviews editor.

Special topics in this edition include Wendy Bacon and Nicole Gooch's Frontline report on Ophir, a new documentary depicting the Bougainville Civil War and Shailendra Singh and Folker Hanusch's 'Watchdogs under Pressure,' a comprehensive research paper on the state of journalism across the Pacific. Kasun Ubayasiri contributes a stunning photoessay on migrant stories from Brisbane, 'Manus to Meanjin: A case study of refugee migration, polymorphic borders and Australian 'imperialism.'

In our main themed section we expose the distortions and outright lies about COVID-19 and vaccines spread online in Fiji by fantasists and conspiracy 
theorists. In 'Spreading (dis)trust in Fiji? Exploring COVID-19 misinformation on Facebook forums,' Romitesh Kant and Rufino Varea examine how Facebook pages have been used as sites for disinformation and sometimes hysterical misreporting in the Fiji coronavirus tragedy.

The worldwide pandemic is also the subject of an article, The COVID-19 pandemic: The resilience of Indonesian journalists by Gilang Desti Parahita, who examines how Indonesian media workers are coping and reporting on the disease. The article argues that mastering journalism data and collaborative work should be embraced to enhance the resilience of the journalists struggling to cover the pandemic, while faced with industrial and political instability.

Reporting on the continuing struggle for West Papuan rights is the subject of two reports. 'Papua and the public: Perception towards news framing of the 2019 Asrama Papua conflict' by Annisa Nadia Putri Harsa and Lily El Ferawati Rofil, who examine reports in the news outlets Kompas and Jubi which display quite different thematic and rhetorical structures. Ana Nadhya Abrar looks at a more positive aspect of the media in 'The role of collaborative journalism in West Papua: A Jubi and Tirto case study', a report on how two news outlets teamed up to report on the conflict.

Elsewhere in this edition of $P J R$, Amanda Watson and Rohan Fox author a study of internet speeds which argues that slow mobile internet speeds could adversely affect media operations and limit the range of voices that can be heard. Reviewers have already noted that the kind of hard data gathered for the article will be valuable for future scholars. Lee Duffield returns with an article on the development of new, independent, online media in Australia that are providing the kind of quality and in-depth journalism conspicuously lacking following years of massive cuts to journalistic staff.

In the Reviews section, the first edited by Nicole Gooch, we look at the subject of our Frontline section, Ophir. David Robie reviews Climate Aotearoa: What's happening and what we can do about it, arguing that action on climate change is becoming even more urgent. Among other publications, Alex Wake reviews Upheaval: Disrupted Lives in journalism, a new book edited by Andrew Dodd and Matthew Ricketson, dealing with the devastation caused to the Australian newspaper industry by the wholesale sacking and forcing out of journalists. Philip Cass reviews a new book on the Lindy Chamberlain case, Feral Media. Belinda Middleweek investigates how the decades' long saga surrounding the disappearance of baby Azaria and claims (finally vindicated) that she was taken by a dingo, became a massive media event in an era when Australian mediaespecially in rural areas - was facing massive changes.

Elsewhere, Ena Manuireva reviews Toxique: Enquête sur les essais nucléaires français en Polynésie, an important book based on an examination of hitherto secret French government files regarding three atomic bomb tests in the 1960s 
and 1970s. A number of new publications are aimed at educators and journalists and PJR veteran Lee Duffield gives his largely positive views on Reuters' new guide to reporting COVID-19. Philip Cass is less enamoured with a new guide from UNESCO on writing about migrants and refugees. While extremely useful in presenting an overall view of the issue, it focuses almost entirely on Europe and Africa and ignores the Pacific completely.

\section{Next issue}

Our next issue will be out in July 2022 and will have 'media change, adaptation and culture' as its theme. The submission deadline is January 20, 2022. Issue editors will be Dr Philip Cass, Khairiah A. Rahman, Nicole Gooch and Dr David Robie.

This special issue of Pacific Journalism Review is linked to the 'Change, Adaptation and Culture: Media and Communication in Pandemic Times' online conference of the Asian Congress for Media and Communication (ACMC) being hosted at Auckland University of Technology on November 25-27. Papers being considered for the July 2021 edition, but which missed out, have been carried forward for the next issue. More information in our Call for Papers on page 320.

DR PHILIP CASS

Editor

Pacific Journalism Review

www.pjreview.info 